Running head: No Sign of Harm

\title{
NO SIGN OF HARM: ISSUES FOR DISABLED CHILDREN COMMUNICATING ABOUT ABUSE.
}

\section{Rebecca Oosterhoorn and Andrew Kendrick}

\author{
Department of Social Work
}

University of Dundee

Address for Correspondence:

Dr. Andrew Kendrick

Senior Lecturer

Department of Social Work

University of Dundee

Dundee DD1 4HN

Telephone, 01382-344739.

Fax, 01382-345573.

email, a.j.kendrick@dundee.ac.uk 


\begin{abstract}
While all children may be the victims of abuse, disabled children are particularly vulnerable. This paper explores the views of professionals working with children using alternative / augmented communication systems on the issues relating to communication about abuse. Interviews were carried out with 20 staff from eight establishments for disabled children across Scotland. It describes the range of alternative / augmented communication systems used and the barriers to communication about abuse. Staff generally accepted the importance of providing the appropriate vocabulary in augmented communication systems, but systems that provide such vocabulary were not widely used. Staff considered that a major difficulty concerned the level of understanding disabled children might have about concepts of abuse. They were unsure how the appropriate vocabulary could be introduced in a natural way and how links could be made between the signs and their meanings. Staff saw themselves as those most able to protect the children, but it was felt that discovery of abuse was more likely to come from them noticing physical signs, behaviour or mood changes than from the child communicating explicitly about abuse. The need for appropriate training and increased coordination between social work, health and education is highlighted.
\end{abstract}

KEY WORDS: disabled children; sexual abuse; child protection; communication 


\section{NO SIGN OF HARM: ISSUES FOR DISABLED CHILDREN COMMUNICATING ABOUT ABUSE}

While all children may be the victims of abuse, disabled children are particularly vulnerable (Morris, 1999; Sullivan and Knutson, 1998, 2000; Westcott and Jones, 1999). Although societal attitudes and myths, particularly that abuse does not happen to disabled children, have contributed to the lack of attention to this area of child protection, these attitudes and myths are increasingly being challenged (Tharinger et al, 1990; Marchant and Page, 1992; Westcott, 1993; Morris, 1999).

Westcott and Jones (1999) identify three core issues in the vulnerability of disabled children: dependency; institutional care; and communication. The dependency of disabled children on a wide network of carers and other involved adults increases their vulnerability. This dependency on carers is often lifelong, and disabled children grow up with people touching them in a private way as a part of daily life. Intimate care activities, such as bathing and toileting, gives a potential abuser a legitimate reason to touch a child. An emphasis on compliance is at the expense of lessons in assertiveness and independence (Anderson, 1982, cited in Tharinger et al, 1990, p. 304).

The use of residential and specialist facilities for disabled children has also been identified by many authors as increasing the likelihood of abuse (Brookhouser et al, 1986; Kelly, 1992a; Kendrick, 1997; Sullivan et al, 1991; Utting, 1991). Many of the disabled adults interviewed in Westcott's (1993) research had spent long periods in hospitals, psychiatric institutions or special schools and 'for this group many of the abusive incidents to be reported occurred in these hospitals and institutions' (Westcott, 1993, p. 14). The interviewees identified the settings they were put into and their experiences in those settings as a factor in their abuse (Westcott, 1993, p. $17)$.

Finally, the issue of communication is central to the protection of disabled children. There are many aspects of abuse which make it difficult for a child to tell about it. Fear, often coupled with a sense of guilt or shame, is a very powerful inhibitor against 
telling of abuse (Wattam and Woodward, 1996). The child can also feel a need to protect the abuser because of emotional ties, which make the child confused and ambivalent about how they feel (Glaser and Frosh, 1988; Salter, 1988). All these mean that telling about abuse is a very difficult process. In relation to disabled children, the scepticism of adults is further increased. Physical appearance and nonverbal communication methods serve to create additional barriers, and Kelly (1992b) gives examples of the defence in court cases focusing on children's disabilities in questioning their evidence. The attempt to communicate about an abusive experience 'may be misunderstood, disregarded, or discredited because of the handicapping condition' (Authier, 1987, p. 237; see also Brookhouser, 1987).

\footnotetext{
'The communication difficulties inherent in many disabilities may render children unable to understand or verbalise episodes of abuse' (Sullivan et al, 1991, p188).
}

These communication difficulties often mean that the child cannot use verbal methods of communication. There are several different methods of communication that may be used by disabled children. However, often these methods of communication lack signs / words relating to sex or body parts (Authier, 1987; Kennedy, 1992), or relating to abuse (Marchant and Page, 1992).

\section{$\underline{\text { The Research }}$}

This study aimed to identify the views of professionals working with children using alternative / augmented communication systems on the issues relating to communication about abuse. The research was exploratory in scope (Robson, 1993). It addresses the ways in which alternative / augmented communication systems are used with disabled children and the barriers to communication about abuse. It also discusses whether and how disabled children are taught about these systems and, linked to this, broader issues of sex education, developmental education and protection work.

Interviews were carried out with 20 staff from eight different establishments, seven schools and one residential respite unit. The schools included a mainstream secondary with a large special education unit; two day schools for children with profound 
learning and/or physical disabilities from age 5 - 19; and four residential schools for children with learning disabilities. The schools were located in five local authority areas across Scotland. Although not all the children in these establishments used alternative methods of communication, this study focused on those who did and the issues this raised for staff with regard to the disclosure of abuse.

The staff interviewed were: two head teachers; two deputy head teachers; 11 teachers and teaching care assistants; two speech therapists; and three residential care workers. They had been working with disabled children from between 2 and 20 years. Without claiming that the sample was representative of all staff working with disabled children, the issues raised by these 'front-line' staff with a range of roles and experience have important implications for policy and practice.

The interviews were semi - structured in nature and a core of 13 questions was used for each interview. All the interviews except four were tape-recorded, then transcribed. Written notes were taken in the four interviews which were not taped. All quotes are as close to the original answers as possible. Analysis focused on identifying common themes from the interviews, and the issues discussed in this paper were addressed by the majority of respondents. Interviews were carried out between September and December 1997 as part of fieldwork for an MSW Dissertation (Oosterhoorn, 1998).

$\underline{\text { Languages and communication systems. }}$

The different languages identified by staff members are shown in Table 1. Makaton (which can be used as an icon-based system displayed on some kind of board or as a sign system) was the most widely used communication system but establishments used a range of systems.

\section{Insert table 1 about here}

A common theme that emerged from all the interviews was that if a specific system such as Makaton, Rebus or Blissymbolics was not appropriate for a child, then staff 
would use photographs, pictures or personalized icons to create a way of communicating.

There are a number of different ways of accessing the languages. The most basic systems are low tech; non-computerized boards with icons, words or pictures displayed in boxes. These boards can have any number of boxes on them depending on the physical and cognitive capabilities of the child. The simplest would have just two choices. Other systems are electronic or computerized and the choice made by a child is spoken in a recorded voice. The simplest of these would be a 'big mac' on which a single message is recorded. A 'big mac' is a large button that incorporates a basic recording element. When pressed, the message is spoken. The message can be changed depending on what the child is being asked to respond to.

A range of computerized systems can use overlays with pictures, icons or words. When the child points to the box chosen, the computer speaks that word or phrase. Again these can be very simple with only two choices or can have a larger number of choices, and software programmes available for these machines allow more complex things to be done with them. The machines can utilize icon- or picture-based languages such as Makaton, Boardmaker or Bliss, or they can use a keyboard of letters and numbers. In the latter case a fairly advanced machine is needed and would use a predictive programme such as 'co-writer'.

The way in which the child accesses the system depends on the system and the child's lever of functioning. With the low-tech boards this would be done by some form of pointing (finger or eye). For the more complex machines access is either direct (touching the choice with a finger or other part of the body), or indirect (through some kind of switch - button, squeeze, cush ball, etc).

\section{Barriers to Communication}


Staff working with disabled children saw them as particularly vulnerable and identified a number of related issues that created barriers to communication about abuse.

As seen above, Makaton was the most widely used communication system and Kennedy (1992) describes Makaton as a "partial language programme in widespread use" (Kennedy, 1992, p172-3). Makaton is developing signs covering general personal growth and development, emotions, feelings and relationships, and with supplementary vocabulary specific to abuse and bullying for sexuality and abuse. These are due to be available in 2002 (Makaton, 2001). A number of staff identified this limitation of vocabulary as a barrier to communication about abuse and, more generally, about sexuality and emotions. Those languages which have appropriate signs for sexuality, development and emotion, Boardmaker, Picture Myself, Talk About and Signalong, were not widely employed across the establishments and their use was dependant on the level of understanding of the child.

Staff frequently raised this issue of the children's level of understanding and how this would affect their ability to communicate about abuse. This was seen as having a number of important aspects. Most respondents expressed the difficulty of teaching complex and abstract concepts of sexuality and developmental education.

'Signalong has a sexuality section. This is still too abstract for some children though' (Teacher / keyworker)

The children in most of the establishments had a combination of disabilities, usually with some level of learning disability. If children found it difficult to make the link with more concrete concepts, respondents were unsure how they could be taught more abstract concepts. This difficulty in understanding was considered by most interviewees to have major implications for teaching disabled children about abuse:

'For any kind of abuse, but particularly sexual, how do you give a child access to that information, how will they disclose, and if you give a child that vocabulary, are they going to use it just because it is there?' (Speech Therapist). 
Importantly, staff also raised the issue of disabled children not understanding that they had been abused.

\begin{abstract}
'An initial problem would be that some of the children wouldn't know whether or not they were in an abusive situation, especially if it was with a trusted person and there was no pain involved' (Teacher)
\end{abstract}

Most staff emphasized the importance of giving children choices in making them less vulnerable, as long as these choices were within their capabilities. However, the children's ability to understand about choices and their cognitive ability to make these choices was often seen as in question:

'We can give choices, but many children do not have the cognitive ability to choose, form an opinion or say they've had enough' (Unit Teacher)

A significant aspect of choice extended to the control carers had over the children's access to vocabulary.

'What words are taught is the educator's choice' (Keyworker).

This was particularly the case when it came to communicating about sex and sexuality and abuse. If a language does not have the appropriate signs for a child then teachers often make their own, but this was also seen as creating further difficulty:

'If the system isn't adequate we will make our own signs but this leaves the problem of consistency and transferability' (Teacher).

The level of control that carers had also extended to the interpretation of what disabled children were saying:

'It depends so much on our interpretation of what they say, sign or draw' (Keyworker). 
Such difficulties have been highlighted in the detailed scrutiny of the interpretation of communication by autistic children through facilitated communication and it is almost always the facilitator who is communicating, not the person with autism' (Jones, 1994; see also, Starr, 1994).

Disabled children's ability to make choices was also seen as being affected by their lack of independence and desire to please carers. Kelly (1992a) sees the nature of many disabilities leading to a need for specialised forms of care which increase the number of potential abusers and the opportunities for abuse (p.160). This was a concern for most of the staff interviewed:

'They are more vulnerable because they have so many different carers. There is a greater risk added to an inconsistent approach' (Assistant Head Teacher).

Staff, then, were very conscious of a range of barriers to disabled children communicating about abuse.

\section{Overcoming the Barriers?}

All respondents stressed the importance of overcoming these barriers to communication but they felt there were no easy answers. Most staff believed that it was important that signs allowing communication of abuse were included on language systems and were taught to children. Some, however, expressed concern over how this could be done in an appropriate manner:

'We must be careful not to put words into their mouths and what signs would you use? It would be controversial and difficult' (Primary teacher).

Similarly, understanding sexuality and personal development was seen as important. While all the establishments attempted to address sex / developmental education, this varied widely. In some cases, more organised approaches were taught to all the children once they reached a certain age: 
'We use the Picture Myself series for sex / developmental education. Usually as far as we go, and as much as they understand, is appropriate / inappropriate touch' (Teacher).

In other establishments a much less structured approach is adopted.

'We would go through public / private places and appropriateness individually... we don't have a sex education programme as such' (Teacher)

A common theme was the importance of gearing sex and personal development education to the understanding of the child and much of this work was done at a basic level of trying to develop body awareness.

Staff struggled for answers to the issues raised in the previous section. They were unsure of how the appropriate vocabulary could be introduced in a natural way and how links could be made between signs and their meanings. Because of this, even though the communication system may have appropriate signs, they are not necessarily accessible to disabled children.

Generally, interviewees considered that the level of awareness of the abuse of disabled children was high and that awareness had increased over recent years. Most establishments had a designated child protection officer who would conduct an initial enquiry and contact outside authorities if necessary and many of the respondents stated that there were clear child protection guidelines and procedures. In addition, most respondents had had some training input on child protection. Staff, however, identified a continuing need for specific child protection training focusing on disabled children.

'I've been to one in-service day which was quite useful, but the children being talked about were not disabled, so it could do with being more appropriate' (Unit Teacher). 
In a survey of residential child care services in Scotland, Lindsay (1999) found that staff in disability services requested training on child protection more frequently than staff in mainstream services (Lindsay, 1999, p. 415)

The increased awareness of abuse also raised common concerns about allegations against staff, particularly in relation to teaching sex education and personal and social development.

'Protecting yourself is a subject that has come up quite a bit. I am very aware not to put myself at risk. I'm definitely more aware of this in recent years...allegations being made...it's in the forefront of people's minds' (Secondary Teacher).

Sullivan et al (1991) states that when working with disabled children, particularly those who have communication difficulties, the adult must be responsible for looking out for and reporting suspected abuse. Given the problems highlighted by those interviewed, they also felt that there needed to be an emphasis on the responsibility of carers and teachers to recognise signs of abuse and protect children. For many an important aspect of this was done by creating an open and accepting environment with close relationships with parents and children.

\section{$\underline{\text { Conclusion }}$}

The vulnerability of disabled children to abuse is becoming increasingly recognised, but there is still a long way to go in closing the gap between child protection services and services for disabled children. This paper has set out the main issues from the perspective of staff working with disabled children.

Awareness of the abuse of disabled children is high among staff and measures are being taken both to try and help the children protect themselves and stress the responsibility of staff to protect disabled children. The importance of providing the appropriate vocabulary in augmented communication systems was generally accepted by staff, but those systems which provide such vocabulary were not widely used in the establishments. Staff did not always know of the developments in communication systems. However, even where such systems were used, staff struggled with the 
difficult issues of enabling disabled children to access signs and concepts of abuse and sexuality. How to get such concepts across to children was seen as one of the biggest barriers to communication about abuse. Putting the vocabulary into the communication systems is needed but is only the first step on a difficult road. Importantly, some disabled children cannot access such systems.

Staff saw themselves as those most able to protect the children because of the amount of daily contact and the close relationship that came from one-to-one work. It was felt that discovery of abuse was more likely to come from them noticing physical signs, behaviour or mood changes, than from the child communicating explicitly about abuse. The central role of staff working with disabled children in protecting them from abuse is crucial. There is an expressed desire to know more about how to protect the children in their care and this could be utilized for the protection of these children. However, training which focuses specifically on child protection issues for disabled children is limited (Ellis and Hendry, 1998)

How to protect disabled children from abuse and reduce their vulnerability is an issue for all the services - social work, health and education. There was a feeling among the respondents that once they took action they were then excluded from the process. They expressed uncertainty about what happens after they involve social workers and felt that they were not kept informed. The Utting report (1997) stated:

'The Council for Disabled Children has called for greater interchange between disability and child protection services, with common training and greater awareness of their respective contributions to protecting children with disabilities' (Utting, 1997, p. 85).

Disabled children are a high-risk group for abuse and this needs to be recognized by child protection workers and the child protection system made more accessible to disabled children. There are changes being made in the establishments where these children live and go to school but increased coordination between social work, health and education is needed for these changes to have any serious impact on the protection of disabled children. 


\section{$\underline{\text { References }}$}

Authier KJ. 1987. The community basis for protecting handicapped children. In Special Children - Special Risks: The Maltreatment of Children with Disabilities, Garbarino J, Brookhouser PE, Authier KJ (eds). Aldine de Gruyter: New York; 231-243

Brookhouser PE. 1987. Ensuring the safety of deaf children in residential schools: Otolaryngology - Head and Neck Surgery, 99: 361-368.

Brookhouser PE, Sullivan P, Scanlan JM, Garbarino J. 1986. Identifying the sexually abused deaf child: the otolaryngologist's role. Laryngoscope, 96: 152158.

Ellis R, Hendry, EB. 1998. Do we all know the score?. Child Abuse Review, 7: 360-363.

Glaser D, Frosh S. 1988. Child Sexual Abuse.: MacMillan Education: Basingstoke.

Jones DPH. 1994. Autism, facilitated communication and allegations of child abuse and neglect. Child Abuse \& Neglect, 18: 491-493.

Kelly L. 1992a. The connections between disability and child abuse: a review of the research evidence. Child Abuse Review, 1: 157-167.

Kelly, L. 1992b. Can't hear or won't hear? - the evidential experience of children with disabilities. Child Abuse Review, 1: 188-190.

Kendrick A. 1997. Safeguarding children living away from home from abuse: a literature review. In Children's Safeguards Review, R. Kent (ed). Scottish Office: Edinburgh; 143-275.

Kennedy M. 1992. Not the only way to communicate: a challenge to voice in child protection work. Child Abuse Review, 1: 169-177.

Lindsay M. 1999. The neglected priority: sexual abuse in the context of residential child care. Child Abuse Review, 8: 405-418. Marchant R, Page, M. 1992. Bridging the Gap: Child Protection Work with Children with Multiple Disabilities. NSPCC: London.

Makaton Vocabulary Development Project. 2001. Personal Growth \& Development, Emotions, Feelings \& Relationships, http://www.makaton.org/resources/rv_personal.htm [15 March 2001]. 
Morris J. 1999. Disabled children, child protection systems and the Children Act 1989: Child Abuse Review, 8, 91-108.

Oosterhoorn R. 1998. Issues for the disclosure of sexual abuse for children using non-verbal communication systems. MSW dissertation, University of Dundee.

Robson C. 1993. Real World Research: A Resource for Social Scientists and Practitioner-Researchers, Blackwell: Oxford.

Salter A. 1988. Treating Child Sexual Offenders and Victims: A Practical Guide, Sage: Newbury Park.

Starr E. 1994. Facilitated communication: a response by child protection. Child Abuse \& Neglect, 18: 515-527.

Sullivan PM, Brookhouser PE, Knutson JF, Scanlan JM, Schulte LE. 1991. Patterns of physical and sexual abuse of communicatively handicapped children. Annals of Otology, Rhinology \& Laryngology, 100: 188-194.

Sullivan PM, Knutson JF. 1998. The association between child maltreatment and disabilities in a hospital-based epidemiological study. Child Abuse \& Neglect, 22: 271-288.

Sullivan PM, Knutson JF. 2000. Maltreatment and disabilities: a populationbased epidemiological study. Child Abuse \& Neglect. 24: 1257-1273.

Tharinger D, Horton CB, Millea S. 1990. Sexual abuse and exploitation of children and adults with mental retardation and other handicaps. Child Abuse \& Neglect, 14, 301-312.

Utting W. 1991. Children in the Public Care: A Review of Residential Child Care. HMSO: London.

Utting W. 1997. People Like Us: The Report on the Review of Safeguards for Children Living Away from Home. The Stationery Office: London.

Wattam C, Woodward C. 1997. 'And do I abuse my children?... No!'. In Childhood Matters: Background Papers Vol. 2, National Commission of Inquiry into the Prevention of Child Abuse. The Stationery Office: London; 143-148. Westcott HL. 1993. Abuse of Children and Adults with Disabilities. NSPCC: London.

Westcott HL, Jones DPH. 1999. Annotation: the abuse of disabled children. Journal of Child Psychology and Psychiatry, 40: 497-506. 


\begin{tabular}{|l|c|}
\hline \multicolumn{2}{|l|}{ Table 1: Augmented communication systems used in the establishments } \\
\hline Communication system & No of establishments \\
\hline Makaton & 7 \\
\hline Rebus & 1 \\
\hline Bliss & 4 \\
\hline Photographs & 2 \\
\hline Literacy & 2 \\
\hline Boardmaker & 1 \\
\hline BSL & 4 \\
\hline Other Icons & 1 \\
\hline Signalong & 2 \\
\hline Pick n Stick & 2 \\
\hline Picture Myself & 1 \\
\hline Talkalong & 2 \\
\hline
\end{tabular}

